\title{
Spontaneous electrical activity of the rat epididymis in vitro
}

\author{
A. Talo, Ulla-Marjut Jaakkola and Merja Markkula-Viitanen \\ Zoophysiological Laboratory, Department of Biology, University of Turku, SF-20500 Turku 50, \\ Finland
}

\begin{abstract}
Summary. Smooth muscle electrical activity was recorded with suction electrodes from the partly or completely uncoiled epididymal duct of the rat in vitro. The electrical activity of the cauda epididymidis consisted of one or few spikes followed by a plateau of 1-2 sec. The frequency of electrical activity declined from the thicker-walled initial segment of the thin-walled initial segment, was increased to the level seen in the initial segment in the thicker, major portion of the caput epididymidis, declined in the corpus and fell steeply in the cauda epididymidis towards the vas deferens. Electrical activity spread over long distances in the distal cauda and epididymal vas. Elsewhere in the epididymis activity remained synchronous only for a short period in short segments.
\end{abstract}

\section{Introduction}

Transport of spermatozoa through the epididymis takes 10-15 days in various species (Amann, Johnson, Thompson \& Pickett, 1976). During transport, the spermatozoa attain fertilizing ability (Bedford, 1975; Orgebin-Crist, 1967). In addition to transport, the epididymis also acts as a reservoir for spermatozoa. The regional variation of structural, physiological and biochemical properties along the epididymis on which maturation and maintenance of spermatozoa could be based has been much studied but the transport mechanism has been little studied. Contractions of the smooth muscle lining the epididymal duct appear to provide the propelling force for the spermatozoa since the transport takes place (1) if fluid flow from the testis is prevented by ligation of the ductuli efferentes (Macmillan \& Auckland, 1960), (2) transport takes place against an increasing hydrostatic pressure gradient from testis to caput and from caput to the cauda (Johnson \& Howards, 1976), and (3) the luminal epithelium is lined with immotile stereocilia (Hamilton, 1975).

Contractions of the epididymal duct have been observed and filmed (Muratori, 1953; Risley, 1958), recorded under isometric conditions in large segments of the epididymis (Hib \& Caldeyro-Barcia, 1974; de Silva e Souza, Gimeno \& Gimeno, 1974) and measured in vivo through an open-ended catheter (Melin, 1970; Knight, 1974; Hib \& Ponzio, 1977). These invivo studies have been limited to the epididymal end of the vas deferens and have shown that contractions are local or peristaltic (Muratori, 1953; Risley, 1958) and their frequency declines from the caput towards the vas deferens (Risley, 1963). The present study was an extension of that by Markkula-Viitanen, Nikkanen \& Talo (1979) and involved in-vitro examination of the electrical activity of all parts of the epididymis of the rat.

\section{Materials and Methods}

Sprague-Dawley male rats at least 2 months old were caged in groups of 3-6. In Exp. 1, the proximal half of the epididymis from the junction of the ductus efferens and the epididymis to the 
beginning of the corpus epididymidis was studied and in Exp. 2 the material was the corpus and cauda epididymidis to the beginning of the vas deferens. In both experiments 20 epididymides, one from each rat, were studied. The rats were killed by cervical dislocation or by decapitation, and the epididymis, testis and a short portion of the vas deferens were removed. The whole complex was kept intact except for the areas which were uncoiled. The epididymal duct was uncoiled to various degrees. After removal of the connective tissue capsule the dissection was made with a pair of fine forceps. By beginning the dissection along the major connective tissue septa the epididymis was revealed as lobes which were covered with a thin layer of connective tissue. At this stage the preparation resembled the final stage of dissection of the guinea-pig epididymis studied by Hoffer \& Greenberg (1978). By tearing along the finer septa the caput was divided into 14 small lobes connected by short regions of straight duct. The final stage of dissection of the caput was subjective but when performed by the same person the results were consistent as shown by a small variation of the duct length in the lobes. In the caput, measurements of the frequency of contractions were made from the lobes and the measurements of the spread of activity were made primarily from the straight segments between the lobes using 6 electrodes. The spread in some small loops in the lobes was also analysed to ascertain that dissection did not alter the characteristics of spread. In the small loops only two or three electrodes could be used simultaneously. In the caput the length of the duct in the lobes was measured after the electrical recordings in 5 epididymides. Since the length of the duct in the lobes was relatively constant such measurements were not made in subsequent epididymides. The results are presented as means of the lobes for the caput. In the corpus and cauda the duct was completely uncoiled. The sites of the first electrode were marked by a loose ligature tied around the duct and the distances of the ligatures from the beginning of the straight portion of the vas deferens were measured after the recordings.

The dissection of the epididymis was made in standard mammalian Ringer solution at room temperature. For the recording the duct was carefully floated in a chamber containing $70 \mathrm{ml}$ Ringer maintained at $36.5^{\circ} \mathrm{C}$ by a thermostatically controlled water jacket. The Ringer solution was slowly exchanged and continuously oxygenated $\left(95 \% \mathrm{O}_{2}, 5 \% \mathrm{CO}_{2}\right)$ and its $\mathrm{pH}$ was $7 \cdot 2$. The duct was allowed to move freely in the bath and was fixed only to the electrodes.

Electrical activity was recorded with 6 small suction electrodes (Talo \& Hodgson, 1978) which had an outer tip diameter of $100-250 \mu \mathrm{m}$. Suction from a water outlet was connected to the electrodes through a large bottle and adjusted experimentally to give the most satisfactory results. Adjustment of the suction and the electrode size was critical for the caput and corpus recordings. Strong suction lead to a rapid decline and disappearance of the electrical activity. Silver wire $(50 \mu \mathrm{m})$ inside the suction electrodes was carefully chloridized before the recordings to minimize polarization phenomena which cause irregular potential changes. A silver-silver chloride reference electrode was connected to the bath through an agar bridge. Electrical activity was recorded on a Grass 6-channel polygraph recorder using AC preamplifiers or on a Mingograf 24B recorder with a Grass P16 DC preamplifier.

\section{Results}

Direct current recordings were made only in the cauda epididymidis in which the amplitude of the signal was sufficiently large. Elsewhere in the epididymis RC filters with various time constants were needed to improve the signal-to-noise ratio. When $\mathrm{DC}$ recordings were made, action potentials consisted of one or few spikes followed by a plateau lasting 1-2 sec (Text-fig. 1). Electrical activity of the caput, corpus and of the proximal cauda had a low amplitude, usually 20-100 $\mu \mathrm{V}$, and its form could not be characterized by this method. The low amplitude could be at least partly explained by the thinness of the smooth muscle layer and by destruction of the cells under the electrodes by suction. This interpretation is supported by the wave form of the 


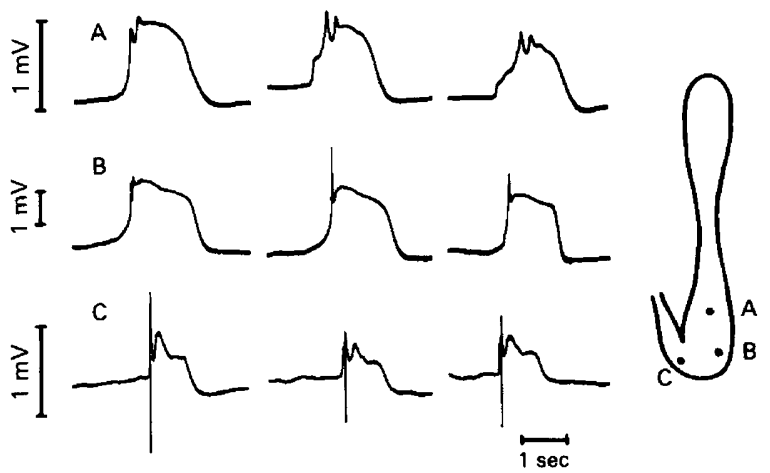

Text-fig. 1. Wave shapes of the spontaneous electrical activity of the cauda epididymidis recorded with the same electrodes in different locations, shown schematically. Three successive waves in each site are illustrated. Recording $\mathrm{A}$ is made in the thin portion of the caudal duct, recording $B$ in the intermediate part and recording $C$ in the thick portion of the caudal duct.

activity. The waves were often of 3 phases, which suggests that the electrodes recorded current spread from the vicinity of the electrodes and not from under the electrodes. Various wave forms recorded in the caput epididymidis are illustrated in Text-fig. 2.

The mean frequencies of the electrical activity along the epididymis are shown in Text-fig. 3. The frequency was 9.5 in the beginning of the duct, which consisted of a section $22 \pm$ 1.9 (s.d.) $\mathrm{cm}$ long $(n=5)$ which had a slightly larger diameter than the next section, $71 \pm$

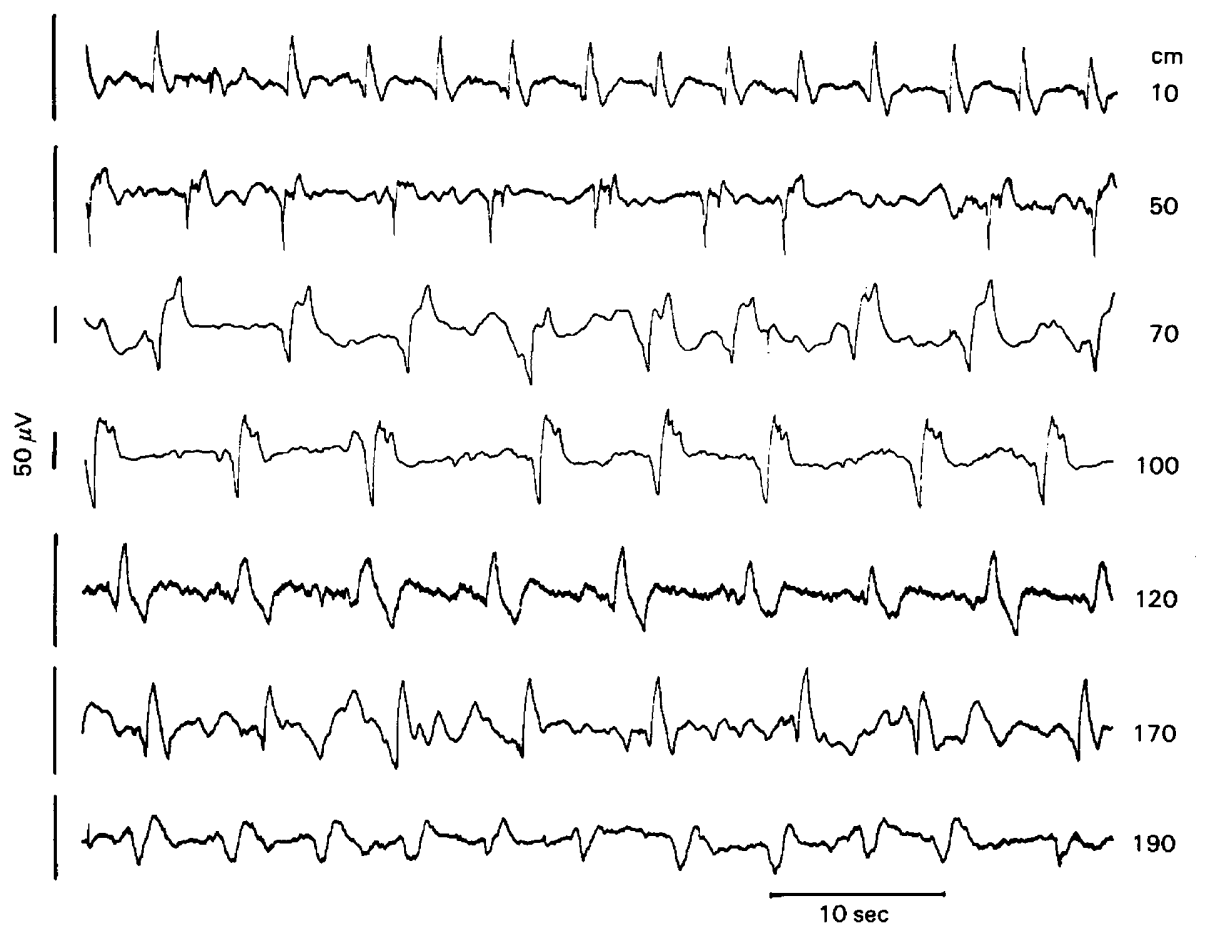

Text-fig. 2. Electrical activity recorded in different parts of the caput epididymidis shown as a composite of recordings from several epididymides. The location of the electrodes from the ductuli efferentes-epididymis junction is shown on the right. The time constants are $0.15 \mathrm{sec}$, except for $0.3 \mathrm{sec}$ in the $50-\mathrm{cm}$ trace. 


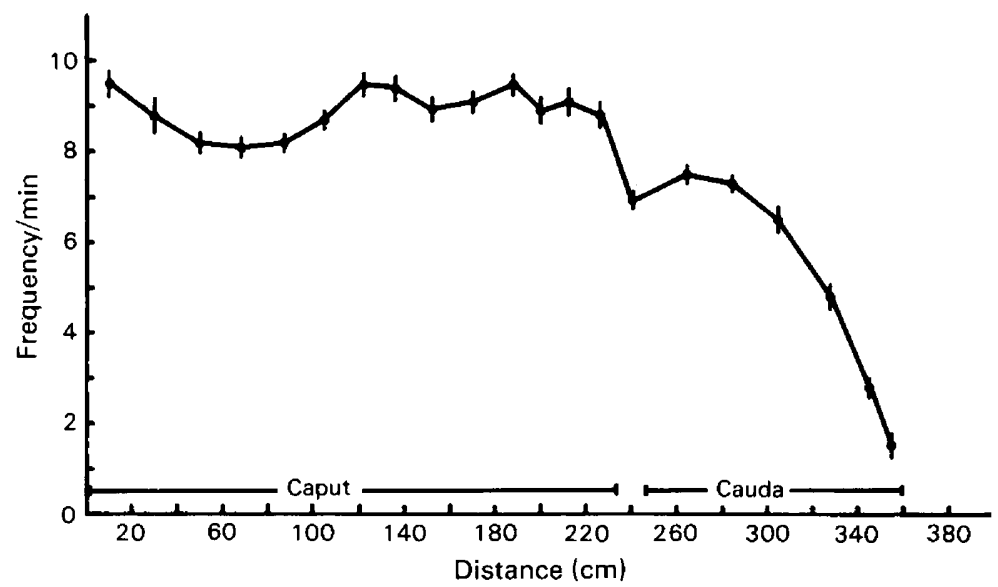

Text-fig. 3. Frequency of electrical activity along the rat epididymis. Means for the caput were measured from 14 lobes and are marked in the middle of the lobes. Measurements of the distance have been made from the beginning of the straight vas deferens for the corpus (single point) and cauda. The epididymal vas is included in the cauda. Each point is a mean of at least 40 measurements in at least 10 epididymides. Vertical bars indicate s.e.m.

$11.6 \mathrm{~cm}$ long, which was the narrowest part of the epididymis. The frequency increased from this narrow portion to the major portion of the caput, which was $129 \pm 4.2 \mathrm{~cm}$ long. Although the absolute differences of frequency were small, the frequency of the narrow segment was significantly lower $(P<0.001)$ than the frequency on both sides of it. The frequency declined from caput to corpus and declined further in the cauda towards the vas deferens.

The electrical activity spread over distances of several centimetres in the epididymal vas deferens and the thick portion of the distal epididymal duct. Even when the electrodes were placed 10-20 mm apart synchronous activity was generally recorded. Text-figure 4 shows propagation of activity in both directions and a discontinuous zone between electrodes 1 and 2, and 5 and 6 . In the middle of the cauda epididymidis there was spread in the direction of the vas deferens and

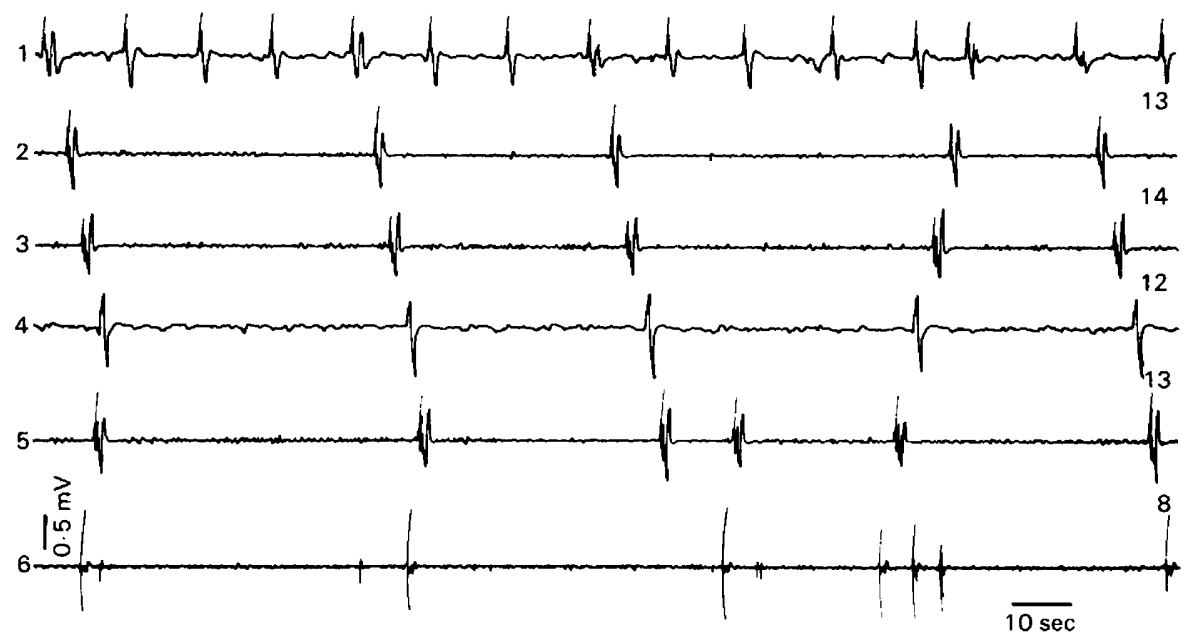

Text-fig. 4. Spread of electrical activity in the distal thick portion of the caudal duct. Activity spreads in both directions but primarily towards the vas deferens and is discontinuous in two areas. The time constant is $1 \mathrm{sec}$ except for channel 6 in which it is $3 \mathrm{sec}$. The electrode distances $(\mathrm{mm})$ are shown on the right. 


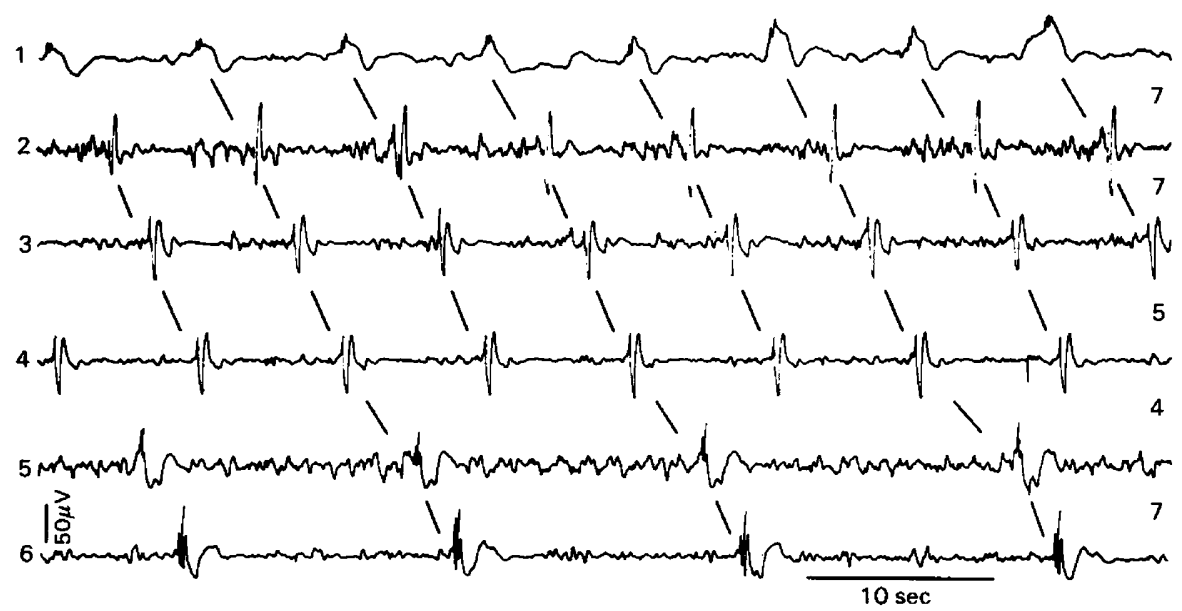

Text-fig. 5. Spread of electrical activity in the middle of the cauda epididymidis. The spread regularly occurs in the direction of the vas deferens, but ceases periodically between electrodes 4 and 5. The time constants are $1 \mathrm{sec}$ on channels $2-6$ and $0.15 \mathrm{sec}$ on channel 1 . The electrode distances $(\mathrm{mm})$ are shown on the right.

cessation of some of the activities (Text-fig. 5). The cessation of the spread was related to the decline of the frequency. In the caput, corpus and proximal cauda the electrical activity never spread over long distances. Even though the electrodes were placed only 1-3 mm apart the activity remained synchronous only for a short period and only in some electrodes. The recording from the thin segment in the beginning of the caput shown in Text-fig. 6 is typical of

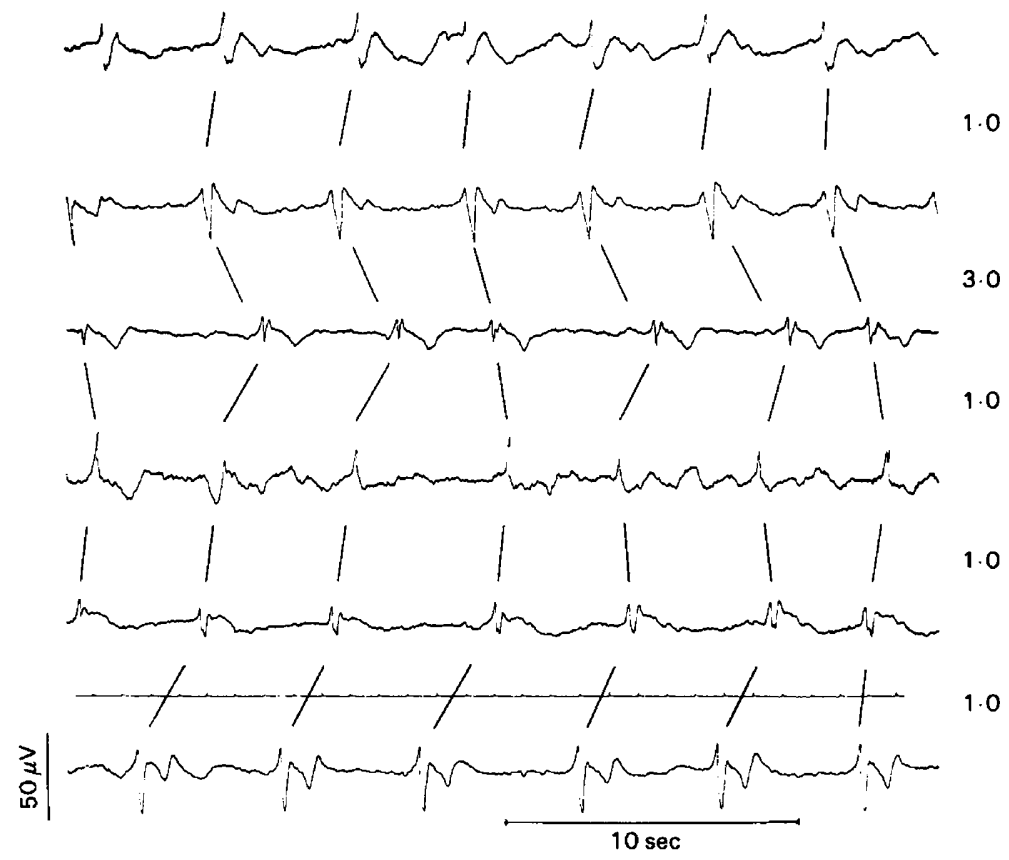

Text-fig. 6. Electrical activity of the proximal thin duct of the caput epididymidis. Lines are drawn to indicate phase changes. The top recording is proximal to the testis and electrode distances $(\mathrm{mm})$ are shown on the right. The time constant is $0.3 \mathrm{sec}$ except for channels 2 and 5 for which it is $0.15 \mathrm{sec}$. 
those made for most of the epididymis. Although the average frequency remained the same there were phase changes which were due to gradual or sudden changes in the interval between the activities. The characteristics of the spread were similar in small loops of the partly dissected duct.

Conduction velocity could be determined only in the distal epididymis. It was highest in the epididymal vas $(5.6 \pm 1.3 \mathrm{~mm} / \mathrm{sec})$ and declined to $3.4 \pm 1.37$ and $1.9 \pm 0.67 \mathrm{~mm} / \mathrm{sec}$ in the distal cauda and to $1.3 \pm 0.81$ to $1.1 \pm 0.41 \mathrm{~mm} / \mathrm{sec}$ in the middle of the cauda. Each value is the mean of at least 10 measurements made in 5 or more epididymides. Elsewhere in the epididymis visual observations of contractions were not possible simultaneously with recording and the phase shifts prevented measurement of conduction velocity from the recordings alone.

\section{Discussion}

The epididymal duct is long, convoluted and packed by connective tissue. Therefore recording of the activity of its smooth muscle requires various degrees of dissection. We uncoiled the corpus and cauda epididymidis completely to measure accurately the site of electrodes and the characteristics of the spread of the activity. In the caput complete uncoiling was impractical because of the thinness of the duct and its length. Since the $230 \mathrm{~cm}$ long caput duct was divided into 14 segments, each consisting of $10-25 \mathrm{~cm}$ of the duct, the presentation of the results as a mean for each lobe was considered sufficiently accurate.

The most stable recordings were obtained in the caudal duct where the wall is thickest. Elsewhere in the epididymis the form of the electrical activity was uncertain and should be studied with microelectrodes. In the cauda the spontaneous activity resembled action potentials recorded in the vas deferens after nerve stimulation (Furness \& Burnstock, 1969) but the plateau did not consist of a postsynaptic potential as found in the vas deferens.

We recorded activity of the epididymis at $36.5^{\circ} \mathrm{C}$ which is about $3^{\circ} \mathrm{C}$ above the temperature of the rat testis (Kormano, 1967). Testicular function is disrupted at the abdominal temperature but less is known about the effects of higher temperature on the epididymis. Bedford (1978) showed that rats in which the cauda epididymis was surgically reflected in the abdominal cavity remained fertile but the spermatozoa confined by ligatures within an abdominal cauda epididymidis rapidly lost their potential for motility. The effects of temperature on speed of propagation are not known. In the canine ureter a decrease of temperature from 37 to $33^{\circ} \mathrm{C}$ results in a decrease of conduction velocity of about $25 \%$ (Butcher, Sleator \& Schmandt, 1957). Since the conduction velocity in the distal cauda epididymidis was low a decrease of about $25 \%$ would not change the numerical values greatly.

Local and peristaltic contractions have been observed in the rat epididymis (Muratori, 1953; Risley, 1958). According to Risley (1963) the majority of the contractions are peristaltic in vivo. Our in-vitro results indicated that peristaltic spread of activity was only present in the distal cauda. It seems likely that elsewhere in the epididymis contractions spread for short distances in absolute terms, although these distances are long in terms of the diameter of the duct. Since invivo observations were possible only from small segments the spread seems peristaltic and therefore there is no disagreement between our results and the earlier observations. The conduction velocity appears to be related to the thickness of the duct or of the muscular wall since the velocity of conduction declined from the epididymal vas towards the testis. It is also possible that it is related to changes in innervation since innervation decreases in the same direction (Risley \& Skrepetos, 1964; Baumgarten, Holstein \& Rosengren, 1971).

The changes in frequency were relatively small in the caput epididymidis. Since the contractions in this area are short relative to the total length of the duct, even small differences in frequency may be important in determining the bias of spread and movements of the luminal contents. However, the flow of the luminal fluid is a complex hydrodynamic process and may 
not be entirely determined by the frequency and spread of contractions. Risley (1963) described the frequency of contractions of the rat epididymis as decreasing towards the vas deferens. Our findings are in general agreement with his observations but provide more detailed data.

\section{References}

Amann, R.P., Johnson, L., Thompson, D.L. \& Pickett, B.W. (1976) Daily spermatozoal production, epididymal spermatozoa reserves and transit time of spermatozoa through the epididymis of the rhesus monkey. Biol. Reprod. 15, 586-592.

Baumgarten, H.G., Holstein, A.F. \& Rosengren, E. (1971) Arrangement, ultrastructure and adrenergic innervation of smooth musculature of the ductuli efferentes, ductus epididymis and ductus deferens of man. Z. Zellforsch. mikrosk. Anat. 120, 37-79.

Bedford, J.M. (1975) Maturation, transport, and fate of spermatozoa in the epididymis. In Handbook of Physiology, Vol. V. Endocrinology. Section 7, Male Reproductive System, pp. 303-317. Eds D. W. Hamilton \& R. O. Greep. Am. Physiol. Soc., Washington, D.C.

Bedford, J.M. (1978) Influence of abdominal temperature on epididymal function in the rat. Am.J. Anat. 152, $509-522$.

Butcher, H.R., Sleator, W. \& Schmandt, W.P. (1957) A study of the peristaltic conduction mechanism in the canine ureter. J. Urol. 78, 221-231.

da Silva e Souza, M.C., Gimeno, M.F. \& Gimeno, A.L. (1974) Spontaneous and testosterone-induced motility of isolated guinea-pig cauda epididymis. Experientia 30, 1063-1065.

Furness, J.B. \& Burnstock, G. (1969) A comparative study of spike potentials in response to nerve stimulation in the vas deferens of the mouse, rat and guinea-pig. Comp. Biochem. Physiol. 31, 337-345.

Hamilton, D.W. (1975) Structure and function of the epithelium lining the ductuli efferentes, ductus epididymis, and ductus deferens in the rat. In Handbook of Physiology, Vol. V, Endocrinology; Section 7, Male Reproductive System, pp. 259-301. Eds D. W. Hamilton \& R. O. Greep. Am. Physiol. Soc., Washington, D.C.

Hib, J. \& Caldeyro-Barcia, R. (1974) Neurohormonal control of epididymal contractions. Basic Life Sci. 4, 11-126.

Hib, J. \& Ponzio, R.O. (1977) Effect of efferent duct ligation, gonadectomy and testosterone replacement on epididymal contractility in the rat. J. Reprod. Fert. 50, 327-329.
Hoffer, A.P. \& Greenberg, J. (1978) The study of the epididymis, efferent ductules and ductus deferens of the guinea pig: a light microscope study. Anat. Rec. $190,659-678$.

Johnson, A.L. \& Howards, S.S. (1976) Intratubular hydrostatic pressure in testis and epididymis before and after long-term vasectomy in the guinea pig. Biol. Reprod. 14, 371-376.

Knight, T.W. (1974) A qualitative study of factors affecting the contractions of the epididymis and ductus deferens in the ram. J. Reprod. Fert. 40, 1929.

Kormano, M. (1967) Development of rectum-testis temperature difference in the post-natal rat. $J$. Reprod. Fert. 14, 427-437.

Macmillan, E.W. \& Aukland, J. (1960) The transport of radio-opaque medium through the initial segment of the rat epididymis. J. Reprod. Fert. 1, 139-145.

Markkula-Viitanen, M., Nikkanen, V. \& Talo, A. (1979) Electrical activity and intraluminal pressure of the cauda epididymidis of the rat. J. Reprod. Fert. 57, 431-435.

Melin, P. (1970) In vivo recording of contractile activity of male accessory genital organs in rabbits. Acta physiol. scand. 79, 109-113.

Muratori, G. (1953) Ulteriori osservazioni sulla motilita spontanea dell epididimo del ratto. Boll. Soc. ital. Biol. sper. 29, 1026-1028.

Orgebin-Crist, M.-C. (1967) Sperm maturation in the rabbit epididymis. Nature, Lond. 216, 816-818.

Risley, P.L. (1958) The contractile behaviour in vivo of the ductus epididymis and vasa efferentia of the rat. Anat. Rec. 130, 471.

Risley, P.L. (1963) Physiology of the male accessory organs. In Mechanisms Concerned with Conception, pp. 73-137. Ed. C. G. Hartman. Pergamon Press, New York.

Risley, P.L. \& Skrepetos, C.N. (1964) Histochemical distribution of cholinesterases in the testis, epididymis and vas deferens of the rat. Anat. Rec. 148, 231241.

Talo, A. \& Hodgson, B.J. (1978) Spike burst in rabbit oviduct. I. Effect of ovulation. Am. J. Physiol. 234, E430-E438. 